\title{
Solubility Determination and Modelling for Milrinone in Binary Solvent Mixtures of Ethanol, Isopropanol, Ethylene Glycol and N,N-Dimethylformamide +
}

\section{Water}

\author{
Jianqiang Zhang ${ }^{1}$, Xin Song ${ }^{2}$, Renjie $\mathrm{Xu}^{*}, 2$
}

${ }^{1}$ Henan Provincial Key Laboratory of Surface \& Interface Science, Zhengzhou University of Light Industry, Henan

450001, People's Republic of China

${ }^{2}$ Guangling College, Yangzhou University, Yangzhou, Jiangsu 225000, People's Republic of China

Corresponding author. Phone: + 86514 87993918; Fax: + 8651487994009.

E-mail address: xurenjie126@163.com 
<smiles>N#Cc1cc(-c2ccncc2)c[nH]c1=O</smiles>

Fig. S1. Chemical structure of milrinone. 


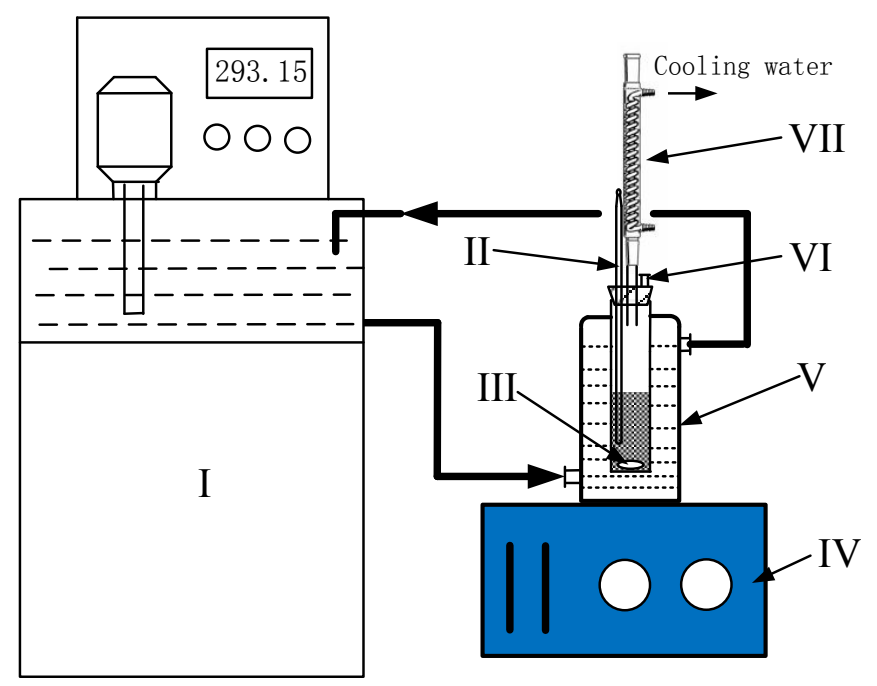

Fig. S2. Schematic diagram of experimental apparatus: I, smart thermostatic water bath; II, mercury-in-glass thermometer; III, magnetic stirrer; IV, stirrer controller; V, jacketed glass vessel; VI, sampling port; VII, condenser. 


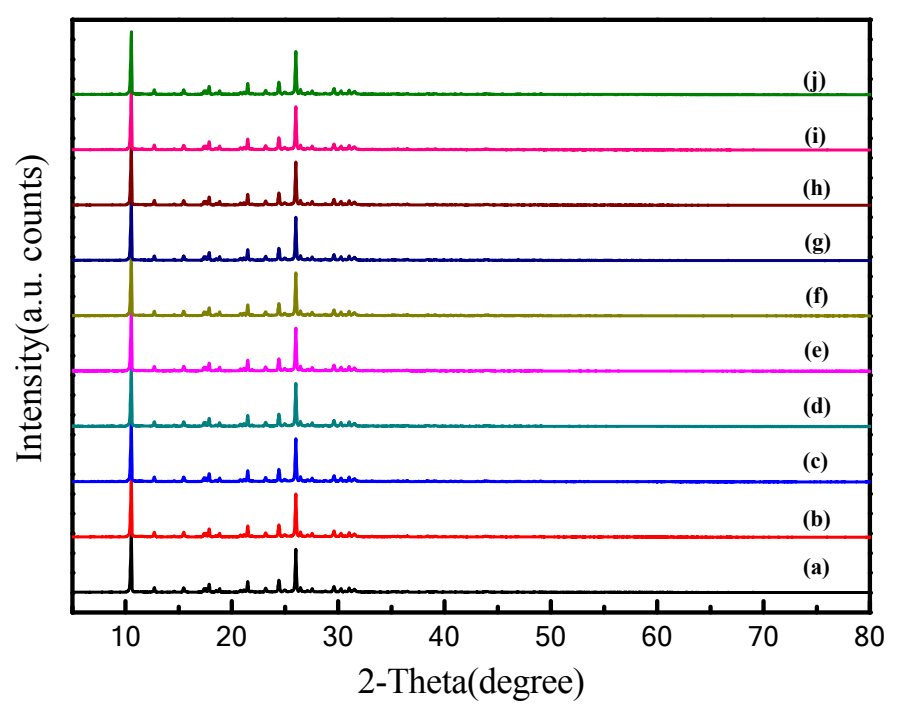

Fig. S3. XPRD patterns of milrinone: (a) raw material; (b) crystallized in ethanol; (c) crystallized in isopropanol; (d) crystallized in EG; (e) crystallized in DMF; (f) crystallized in water; (g) crystallized in ethenol (1) + water (2) mixture; (h) crystallized in isopropanol (1) + water (2) mixture; (i) crystallized in EG (1) + water (2) mixture; (j) crystallized in DMF (1) + water (2) mixture. 